\title{
Carbon dioxide forcing alone insufficient to explain Palaeocene-Eocene Thermal Maximum warming
}

\author{
Richard E. Zeebe ${ }^{1 \star}$, James C. Zachos ${ }^{2}$ and Gerald R. Dickens ${ }^{3}$
}

The Palaeocene-Eocene Thermal Maximum (about 55 Myr ago) represents a possible analogue for the future and thus may provide insight into climate system sensitivity and feedbacks ${ }^{1,2}$. The key feature of this event is the release of a large mass of ${ }^{13} \mathrm{C}$-depleted carbon into the carbon reservoirs at the Earth's surface, although the source remains an open issue ${ }^{3,4}$. Concurrently, global surface temperatures rose by $5-9{ }^{\circ} \mathrm{C}$ within a few thousand years ${ }^{5-9}$. Here we use published palaeorecords of deep-sea carbonate dissolution ${ }^{10-14}$ and stable carbon isotope composition ${ }^{10,15-17}$ along with a carbon cycle model to constrain the initial carbon pulse to a magnitude of $3,000 \mathrm{PgC}$ or less, with an isotopic composition lighter than $-50 \%$. As a result, atmospheric carbon dioxide concentrations increased during the main event by less than about $70 \%$ compared with pre-event levels. At accepted values for the climate sensitivity to a doubling of the atmospheric $\mathrm{CO}_{2}$ concentration ${ }^{1}$, this rise in $\mathrm{CO}_{2}$ can explain only between 1 and $3.5^{\circ} \mathrm{C}$ of the warming inferred from proxy records. We conclude that in addition to direct $\mathrm{CO}_{2}$ forcing, other processes and/or feedbacks that are hitherto unknown must have caused a substantial portion of the warming during the PalaeoceneEocene Thermal Maximum. Once these processes have been identified, their potential effect on future climate change needs to be taken into account.

The magnitude of future global warming from anthropogenic $\mathrm{CO}_{2}$ forcing remains unknown because of uncertainties in predicting climate system feedbacks ${ }^{1}$. Studying past episodes of global warming and rapid carbon release such as the Palaeocene-Eocene Thermal Maximum (PETM) may help to reduce those uncertainties or at least isolate the possible sources ${ }^{2}$. The onset of the PETM was marked by a global increase in surface temperatures by $5-9{ }^{\circ} \mathrm{C}$ within a few thousand years ${ }^{5-9}$. At nearly the same time, a substantial carbon release occurred, as demonstrated by a large drop in the ${ }^{13} \mathrm{C} /{ }^{12} \mathrm{C}$ ratio of surficial carbon reservoirs. The carbon release led to ocean acidification and widespread dissolution of deep-sea carbonates ${ }^{10,18}$. Different sources for the carbon input have been suggested, which has led to speculations concerning the mechanism. Some, such as volcanic intrusion, imply that the carbon drives the warming. Others, such as the destabilization of oceanic methane hydrates, imply that the carbon release is a feedback that can exacerbate warming ${ }^{3,4,19}$. Remarkably, however, even the lower estimates for the carbon release during the onset of the PETM $\left(\sim 1 \mathrm{PgCy}^{-1}\right)$ and over the past 50 years from anthropogenic sources seem to be of a similar order of magnitude (see the Methods section). The PETM may therefore serve as a case study for the consequences of the carbon dioxide released at present by human activities.

We have used deep-sea carbonate dissolution records ${ }^{10-14}$ and stable carbon isotope records across the PETM (refs 10, 15-17) in combination with carbon cycle modelling ${ }^{2,18,20}$ to constrain the mass of the PETM carbon input (Fig. 1). The observed drop in the stable carbon isotope composition $\left(\delta^{13} \mathrm{C}\right)$ of the surficial carbon reservoirs is about $3 \%$. However, the $\delta^{13} \mathrm{C}$ signal alone is insufficient to determine the mass and $\delta^{13} \mathrm{C}$ value of the carbon input. In this study, the input mass is estimated from carbonate dissolution records. The $\delta^{13} \mathrm{C}$ composition of this carbon was then constrained by requiring the model outcome to match observed marine $\delta^{13} \mathrm{C}$ records at the given input mass (see Supplementary Information). For our model simulations, we used the longterm ocean-atmosphere-sediment carbon cycle reservoir model LOSCAR (see refs 2, 18, 20 and Supplementary Information).

To simulate the observed time-dependent profile (that is, magnitude and duration) of the carbon isotope excursion (CIE) during the PETM main phase (Fig. 1b,c), we assumed a large initial input pulse followed by further smaller pulses and a low, continuous carbon release during the main event (Fig. 1a). Without the further release, the model was unable to reproduce the CIE duration because $\delta^{13} \mathrm{C}$ values returned to pre-excursion values too quickly (Fig. 1b, dotted green line). A pulsed carbon release (rather than a single input peak) is consistent with $\delta^{13} \mathrm{C}$ records from most marine and terrestrial sections $s^{21,22}$.

The prolonged carbon release is also important to simulate the observed duration of deep-sea carbonate dissolution (Fig. 1d-f). For example, the carbonate records from Walvis Ridge in the Atlantic Ocean show that wt $\% \mathrm{CaCO}_{3}$ values at various palaeowater depths return to pre-excursion values only after more than $70 \mathrm{kyr}$ (Fig. 1e). The extended duration of the dissolution event could not be reproduced in the model without the continued carbon release (Fig. 1d).

The size of the carbon input, on the other hand, is determined by the magnitude of $\mathrm{CaCO}_{3}$ dissolution or shoaling of the calcite compensation depth (CCD) in the different ocean basins (Fig. 1f,g). Note that for the quantification of the carbon input, the position of the CCD before the event is as critical as the actual shoaling. For example, the late Palaeocene CCD was about $1-1.5 \mathrm{~km}$ shallower than today in all ocean basins, including the Pacific basin, which was much larger than today (see refs 23, 24 and references therein). Just before the event, Ocean Drilling Program core sites 1208 (Pacific Shatsky Rise) and 1221 (Equatorial Pacific) at 3,350 m and 3,200 $\mathrm{m}$ palaeowater depth, respectively, were located very close to the CCD, indicating a Pacific pre-event CCD shallower than $3,500 \mathrm{~m}$. This depth is consistent with other reconstructions ${ }^{11,23}$ (see Supplementary Fig. S5). In the late-Palaeocene Pacific basin, the erodible sediment $\mathrm{CaCO}_{3}$ inventory in the depth range $3.5-4.5 \mathrm{~km}$ would have been $\sim 2,000 \mathrm{Pg} \mathrm{C}$, which has the capacity to neutralize $\sim 2,200 \mathrm{PgC}$ of $\mathrm{CO}_{2}$ (see the Methods section). Setting the preevent CCD at a depth below that indicated by observations

\footnotetext{
${ }^{1}$ School of Ocean and Earth Science and Technology, Department of Oceanography, University of Hawaii at Manoa, 1000 Pope Road, MSB 504, Honolulu, Hawaii 96822, USA, ${ }^{2}$ Earth and Planetary Sciences Department, University of California, Santa Cruz, California 95064, USA, ${ }^{3}$ Department of Earth Sciences, Rice University, Houston, Texas 77005, USA. *e-mail: zeebe@soest.hawaii.edu.
} 
a

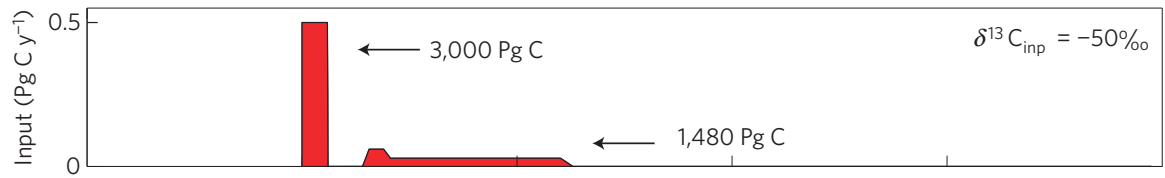

b

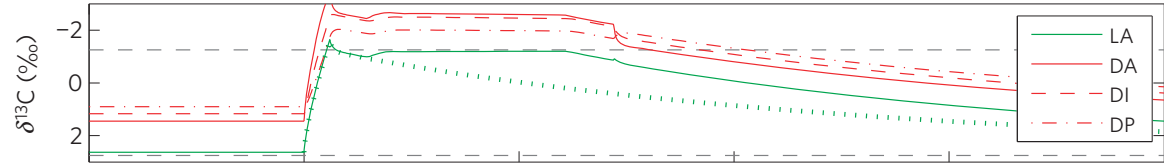

c
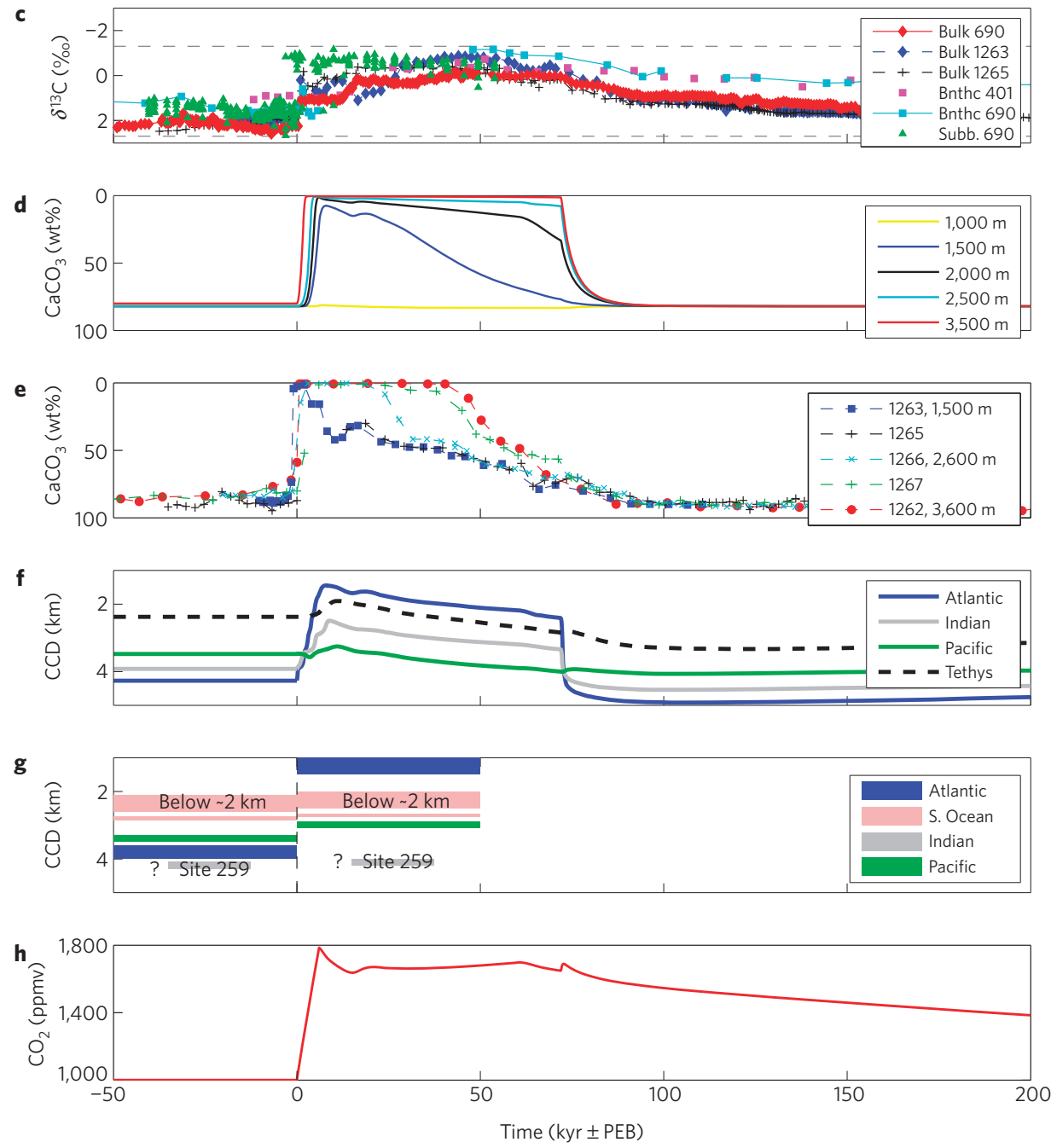

Figure 1 | PETM model simulations and palaeorecords. a, PETM carbon-release scenario (model input); $t=0$ corresponds to the onset of the PETM. b. Simulated $\delta^{13} \mathrm{C}_{\text {of }} \mathrm{TCO}_{2}$ in the low-latitude surface Atlantic (LA), deep Atlantic, Indian and Pacific oceans (DA, DI, DP) using the carbon release shown in $\mathbf{a}$, including the continuous release (solid green and red lines). In simulations without the continuous release (dotted green line), the duration of the $\delta^{13} \mathrm{C}$

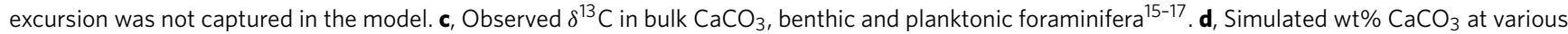
depths in the deep Atlantic. e, Observed wt $\% \mathrm{CaCO}_{3}$ at Walvis Ridge, South Atlantic Ocean ${ }^{10}$. f, Simulated CCD in different basins. $\mathbf{g}$, Observed CCD before and during the PETM main event (see Supplementary Information). $\mathbf{h}$, Simulated atmospheric $\mathrm{CO}_{2}$ (PEB: Palaeocene/Eocene boundary).

would therefore erroneously increase the available $\mathrm{CaCO}_{3}$ for dissolution/erosion and lead to a significant overestimate of the carbon input ${ }^{25}$. During the event, the Atlantic CCD shoaled markedly by at least $2 \mathrm{~km}$ (Fig. $1 \mathrm{e})^{10}$, whereas the Pacific CCD shoaled by only a few hundred metres (see refs $11,13,14,18$ and Supplementary Information).

To simulate the profound differences in observed Atlantic and Pacific CCD changes, we made additional assumptions on the basis of earlier suggestions (the model sensitivity to these assumptions is examined in Fig. 2). First, we assumed a partial carbon injection directly into the deep Atlantic ${ }^{3}$. Second, we assumed a steady contribution of North Pacific Deep Water (NPDW) formation during the event ${ }^{26}$, which makes Atlantic deep waters more corrosive $^{18}$ (the Southern Ocean source remains active but is reduced relative to its pre-event strength). Both processes enhance carbonate dissolution in the deep Atlantic. Without NPDW, the Atlantic CCD shoaling in the model is too small relative to observations, even at a total carbon input of $4,000 \mathrm{PgC}$ and 
a
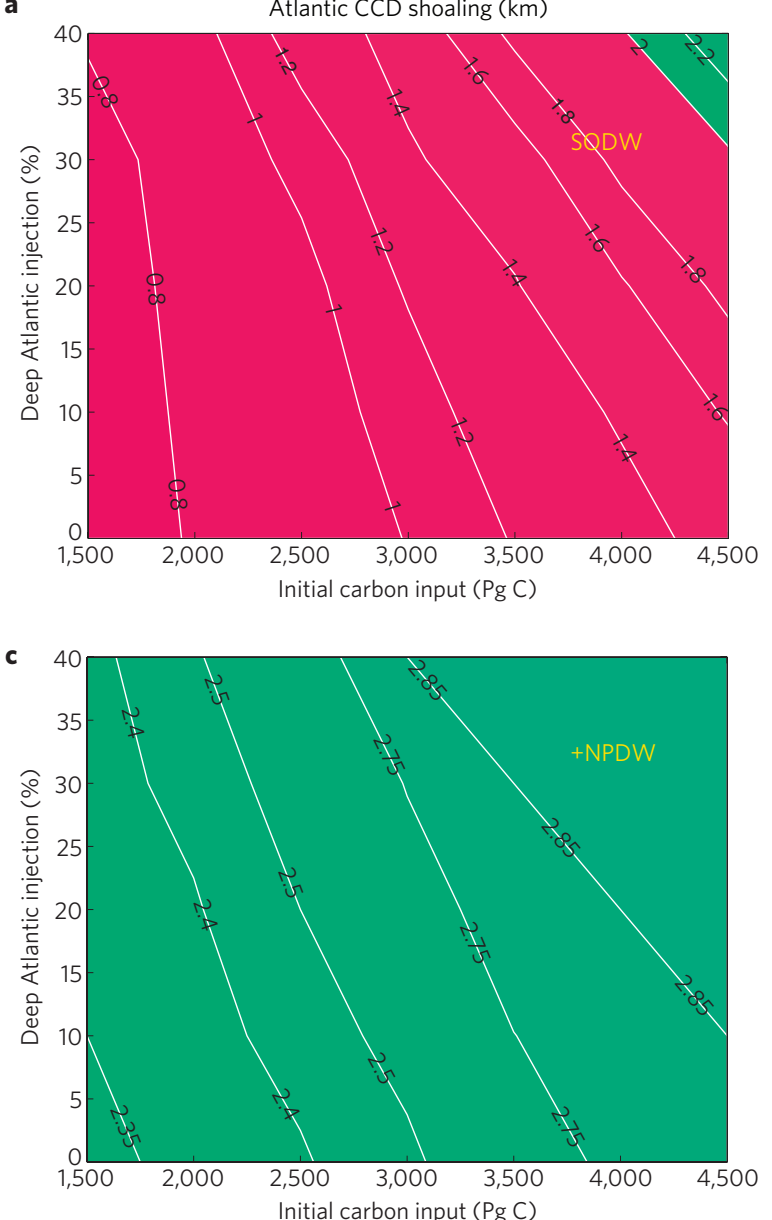
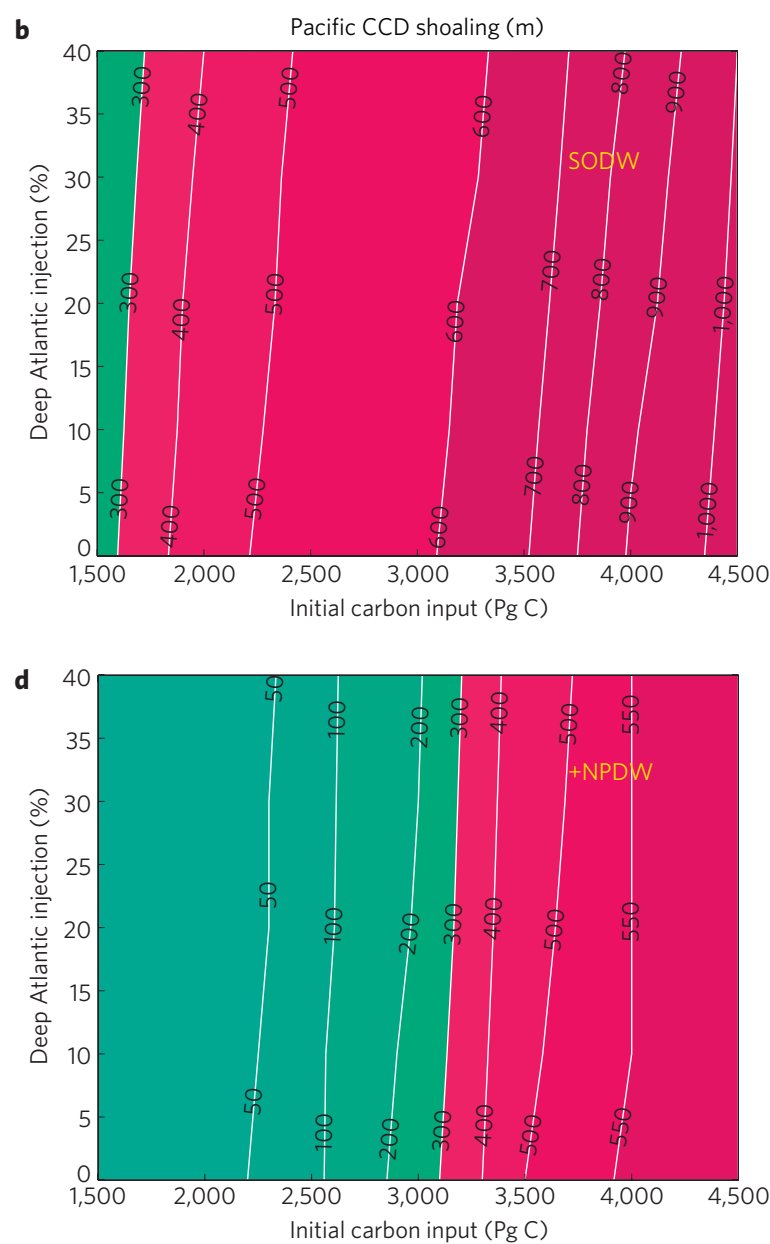

Figure 2 | Simulated CCD shoaling. CCD shoaling as a function of initial carbon input (see Fig. 1a) and \%carbon injected into the deep Atlantic. The green and red areas indicate data compatibility and incompatibility, respectively. a, Atlantic CCD shoaling (in km) with a global Southern Ocean Deep Water (SODW) source. b, Pacific CCD shoaling (in $\mathrm{m}$ ) with SODW alone. c, Atlantic CCD shoaling when a contribution of North Pacific Deep Water (NPDW) is included. d, Pacific CCD shoaling including NPDW.

$40 \%$ direct injection into the deep Atlantic (Fig. 2a). To match observations, total input and/or direct injection into the deep Atlantic must be greater (green and red areas in Fig. 2 indicate data compatibility and incompatibility, respectively). However, such scenarios lead to excessive CCD shoaling in the Pacific (inconsistent with the data; red area in Fig. 2b). Alternatively, with NPDW, the simulated CCD shoaling in the Atlantic is consistent with observations for all input scenarios between 1,500 and 4,500 Pg C (Fig. 2c). The maximum initial input is constrained to $\sim 3,000 \mathrm{Pg} \mathrm{C}$ by the observed CCD shoaling of less than $\sim 300 \mathrm{~m}$ in the Pacific (green area in Fig. 2d). This estimate of the maximum initial carbon input is largely independent of its duration (see Supplementary Fig. S1).

An additional key model benchmark (in addition to simulating adequate $\delta^{13} \mathrm{C}$ and CCD changes) is to replicate the reconstructed deep-sea $\left[\mathrm{CO}_{3}^{2-}\right]$ gradient between the different ocean basins ${ }^{18}$. This basin gradient was reversed during the PETM relative to the modern. That is, during the PETM main phase, the most corrosive deep water resided in the Atlantic and not in the Pacific as today (Fig. 3a). Observations indicate that deep $\left[\mathrm{CO}_{3}^{2-}\right]$ in the Pacific was about 1.5 times higher than in the South Atlantic. This ratio is reproduced by our model (Fig. 3b).

In summary, using the rate of carbon input shown in Fig. 1a and the input location and circulation changes discussed above, the model captures the essential features of the observed carbon isotope and deep-sea dissolution records. This constrains the initial
PETM carbon input to less than 3,000 Pg C, as a larger input would lead to more intense dissolution, particularly in the Pacific, which is not supported by the data. The magnitude of the CIE then requires the isotopic composition of the carbon input to be lighter than $-50 \%$, consistent with a highly ${ }^{13} \mathrm{C}$-depleted source such as biogenic methane. (Note that methane would have been oxidized rapidly to $\mathrm{CO}_{2}$ in the water column and/or the atmosphere ${ }^{3}$.) The pattern of the carbon input scenario required by the model to match observations (Fig. 1a) seems to be consistent with carbon release from oceanic gas hydrate reservoirs. The pulsed input pattern could indicate carbon release from different ocean basins or depth horizons containing gas hydrate ${ }^{21}$. The continued release could be explained by non-steady-state fluxes from marine gas hydrate systems following the initial dissociation of gas hydrate $e^{27}$ or fluxes from marine/terrestrial sedimentary reservoirs.

As a result of the carbon input, we calculate an increase in atmospheric $\mathrm{CO}_{2}$ from a baseline of 1,000 ppmv to $\sim 1,700 \mathrm{ppmv}$ during the PETM main phase (Fig. 1h) (a baseline $p \mathrm{CO}_{2}$ several times higher than the pre-industrial value is generally accepted as the PETM is superimposed on a much warmer climate $\left.{ }^{4,24}\right)$. Thus, if initiated at a baseline $\mathrm{CO}_{2}$ of 1,000 ppmv, $\mathrm{CO}_{2}$ increases by a factor of $\sim 1.7$. We found this factor to be largely independent of the assumed baseline $\mathrm{CO}_{2}$, for instance, at $500,1,000$ or $1,500 \mathrm{ppmv}$.

At the accepted equilibrium climate sensitivities of $1.5-4.5^{\circ} \mathrm{C}$ warming per doubling of $\mathrm{CO}_{2}$ (ref. 1), our calculated 1.7-fold increase in $\mathrm{CO}_{2}$ would at most have caused $\sim 3.5^{\circ} \mathrm{C}$ warming 

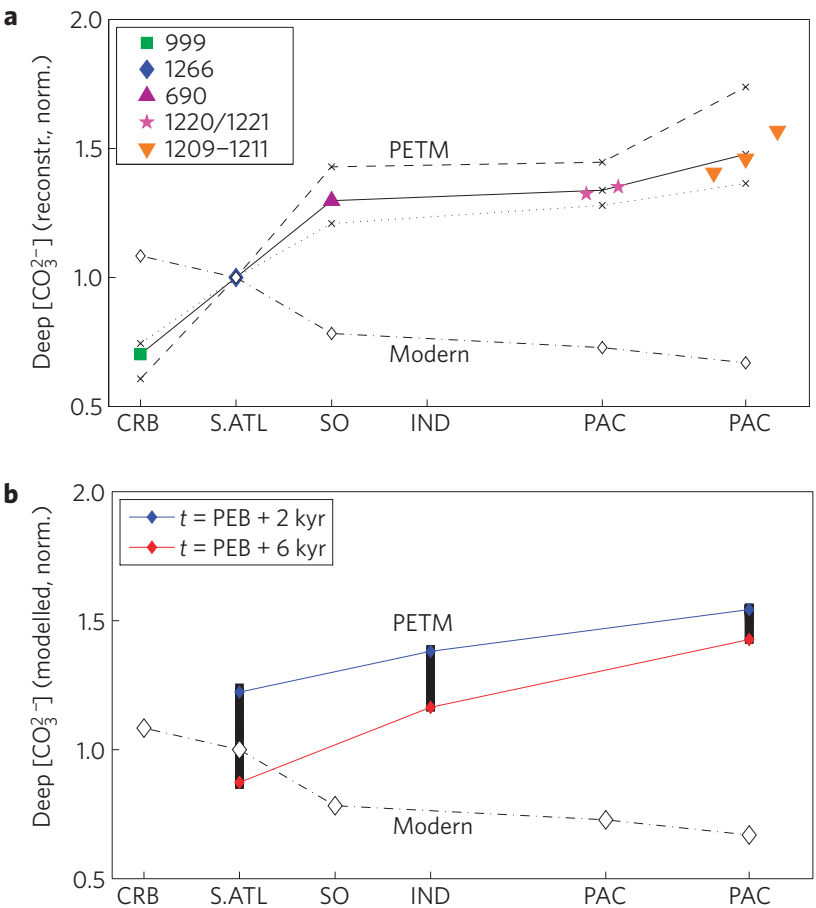

Figure 3 | Deep-sea carbonate ion basin gradient during the PETM.

a, Reconstruction based on carbonate records from different sites (colour symbols, as indicated) ${ }^{18}$. b. Simulation from our carbon cycle model (blue and red lines) at 2 and $6 \mathrm{kyr}$ after the onset of the PETM $(t=0)$. The black bars indicate the range of the simulated gradient at different times. The open diamonds in $\mathbf{a}, \mathbf{b}$ show the corresponding gradient based on modern observations. Deep-sea $\left[\mathrm{CO}_{3}^{2-}\right]$ concentrations are normalized to the concentration in the South Atlantic Ocean. CRB: Caribbean, S.ATL: South Atlantic Ocean, SO: Southern Ocean, IND: Indian Ocean, PAC: Pacific Ocean, PEB: Palaeocene/Eocene boundary.

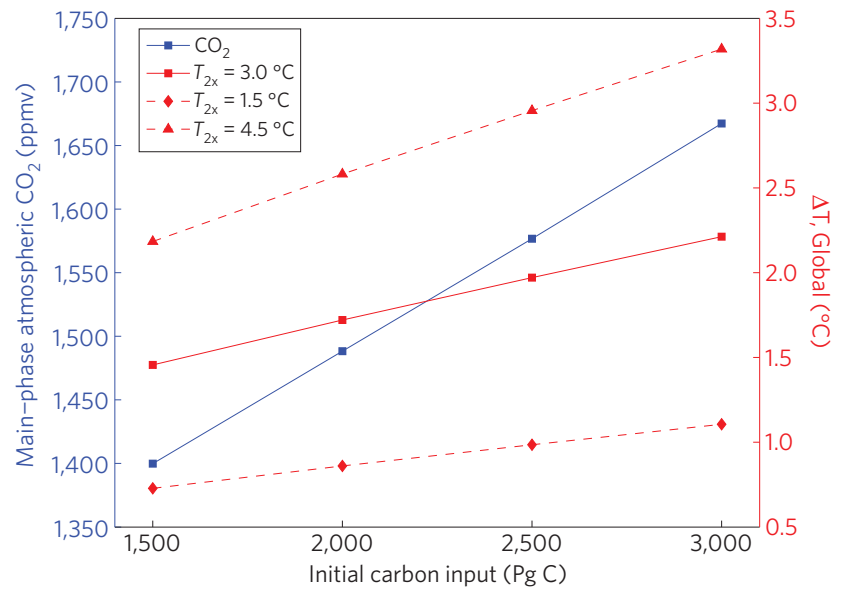

Figure 4 | Simulated atmospheric $\mathrm{CO}_{\mathbf{2}}$ during the main event. Average $\mathrm{pCO}_{2}$ over $70 \mathrm{kyr}$ (see Fig. 1h) as a function of initial carbon input (blue, left axis); pre-PETM CO 2 is 1,000 ppmv. The red graphs (right axis) show the calculated global temperature increase based on different climate sensitivities. Note that whereas peak atmospheric $\mathrm{CO}_{2}$ is a nonlinear function of the carbon input, the '70 kyr-average' increase is nearly linear over the range shown. The percentage of deep Atlantic injection has little effect on the '70 kyr-average'.

during the PETM main phase (Fig. 4). This constitutes an enigma because proxy records globally indicate surface warming by $5-9{ }^{\circ} \mathrm{C}$ (refs 5-9). If the temperature reconstructions are correct, then feedbacks and/or forcings other than atmospheric $\mathrm{CO}_{2}$ caused a major portion of the PETM warming. The origin of this additional warming is unknown at present. Possible causes of the excess warming include increased production and levels of trace greenhouse gases as a consequence of the climatic warming (such as $\mathrm{CH}_{4}$; ref. 28). Regardless, this mismatch poses a challenge for our understanding of past episodes of strong and rapid global warming. Undoubtedly, the climatic boundary conditions before the PETM were different from today's-including different continental configuration, absence of continental ice and a different base climate, which limits the PETM's suitability as the perfect future analogue. Nevertheless, our results imply a fundamental gap in our understanding of the amplitude of global warming associated with large and abrupt climate perturbations. This gap needs to be filled to confidently predict future climate change.

\section{Methods}

The PETM carbon release rate was estimated using our initial carbon input of $3,000 \mathrm{Pg} \mathrm{C}$ and an input timescale of the order of 5,000 years (ref. 29), giving a rate of $\sim 0.6 \mathrm{PgCy}^{-1}$. The average carbon release rate from fossil-fuel burning and cement manufacturing from 1954-2004 is $\sim 5 \mathrm{Pg} \mathrm{Cy}^{-1}$ (ref. 30).

Given a Palaeocene/Eocene bathymetry ${ }^{26}$, the Pacific seafloor area between 3.5 and $4.5 \mathrm{~km}$ depth can be estimated as $A_{\Delta z}=A_{\mathrm{oc}} \cdot a_{\mathrm{P}} \cdot a_{\Delta z} \simeq 5.5 \times 10^{13} \mathrm{~m}^{2}$, where $A_{\mathrm{oc}} \simeq 3.5 \times 10^{14} \mathrm{~m}^{2}$ is the area of the ocean, $a_{\mathrm{p}} \simeq 0.52$ is the Palaeocene/Eocene Pacific fraction and $a_{\Delta z} \simeq 0.30$ is the Pacific area fraction between 3.5 and $4.5 \mathrm{~km}$ depth. The calcite inventory in the top sediment layer of thickness $h$ over this area is given by $M_{\mathrm{cal}}=A_{\Delta z} h \rho f_{\mathrm{c}}(1-\phi)$, where $\rho=2,500 \mathrm{~kg} \mathrm{~m}^{-3}$ is the sediment density, $f_{\mathrm{c}}$ is the calcite dry weight fraction and $\phi$ is the porosity. Using $f_{c}=0.9$ and $\phi=0.7$ and converting to carbon units, we have $M_{\mathrm{C}}=M_{\text {cal }} \times 12 / 100 \simeq 440 \mathrm{Pg}$ C. The erodible calcite is larger than the surface inventory by a factor $\left[1+r_{\phi} f_{\mathrm{c}} /\left(1-f_{\mathrm{c}}\right)\right]$, where $r_{\phi} \simeq 0.4$ (ref. 18). Thus, the erodible $\mathrm{CaCO}_{3}$ inventory in the late Palaeocene Pacific in the depth range $3.5-4.5 \mathrm{~km}$ would have been about $2,000 \mathrm{Pg}$ C.

Restoring the carbonate ion concentration $\left(\mathrm{CO}_{2}\right.$ neutralization) by deep-sea $\mathrm{CaCO}_{3}$ dissolution in response to $\mathrm{CO}_{2}$ acidification requires about $0.9 \mathrm{~mol}$ $\mathrm{CaCO}_{3}$ dissolved per mol $\mathrm{CO}_{2}$ added. For example, adding $100 \mu \mathrm{mol} \mathrm{kg}{ }^{-1} \mathrm{CO}_{2}$ to a seawater sample at $\left[\mathrm{TCO}_{2}, \mathrm{TA}\right]=[2.3,2.4] \mathrm{mmol} \mathrm{kg}^{-1}\left(\mathrm{~T}, \mathrm{~S}, \mathrm{P}=10^{\circ} \mathrm{C}, 35\right.$, $350 \mathrm{bar})$, reduces $\left[\mathrm{CO}_{3}^{2-}\right]$ from 84 to $42 \mu \mathrm{mol} \mathrm{kg}{ }^{-1}\left(\mathrm{TCO}_{2}\right.$ : total dissolved inorganic carbon, TA: total alkalinity, T: temperature, S: salinity, P: pressure). Dissolution of $92 \mu \mathrm{mol} \mathrm{kg}{ }^{-1} \mathrm{CaCO}_{3}$ restores $\left[\mathrm{CO}_{3}^{2-}\right]$ back to $84 \mu \mathrm{mol} \mathrm{kg}{ }^{-1}$.

Received 16 April 2009; accepted 13 June 2009; published online 13 July 2009

\section{References}

1. IPCC. Climate Change 2007: The Physical Science Basis (eds Solomon, S., et al.) (Cambridge Univ. Press, 2007).

2. Zachos, J. C., Dickens, G. R. \& Zeebe, R. E. An early Cenozoic perspective on greenhouse warming and carbon-cycle dynamics. Nature 451, 279-283 (2008).

3. Dickens, G. R. Methane oxidation during the late Palaeocene Thermal Maximum. Bull. Soc. Geol. Fr. 171, 37-49 (2000).

4. Pagani, M., Calderia, K., Archer, D. \& Zachos, J. C. An ancient carbon mystery. Science 314, 1556-1557 (2006).

5. Kennett, J. P. \& Stott, L. D. Abrupt deep-sea warming, palaeoceanographic changes and benthic extinctions at the end of the Palaeocene. Nature 353, 225-229 (1991)

6. Zachos, J. C. et al. A transient rise in tropical sea surface temperature during the Paleocene-Eocene Thermal Maximum. Science 302, 1551-1554 (2003).

7. Tripati, A. \& Elderfield, H. Deep-sea temperature and circulation changes at the Paleocene-Eocene Thermal Maximum. Science 308, 1894-1898 (2005).

8. Zachos, J. C. et al. Extreme warming of mid-latitude coastal ocean during the Paleocene-Eocene Thermal Maximum: Inferences from $\mathrm{TEX}_{86}$ and isotope data. Geology 34, 737-740 (2006).

9. Sluijs, A. et al. Subtropical Arctic Ocean temperatures during the Palaeocene/Eocene Thermal Maximum. Nature 441, 610-613 (2006).

10. Zachos, J. C. et al. Rapid acidification of the ocean during the Paleocene-Eocene Thermal Maximum. Science 308, 1611-1615 (2005).

11. Lyle, M., Wilson, P. A. \& Janecek, T. R. Leg 199 summary. Proc. ODP Init. Rep. 199, 1-87 (2002).

12. Farley, K. A. \& Eltgroth, S. F. An alternative age model for the Paleocene-Eocene Thermal Maximum using extraterrestrial ${ }^{3}$ He. Earth Planet Sci. Lett. 208, 135-148 (2003)

13. Colosimo, A. B., Bralower, T. J. \& Zachos, J. C. in Proc. ODP, Sci. Results Vol. 198 (eds Bralower, T. J., Premoli Silva, I. \& Malone, M. J.) (Texas A\&M Univ., 2005).

14. Murphy, B., Lyle, M. \& Lyle, A. O. in Proc. ODP, Sci. Res. (eds Wilson, P. A., Lyle, M. \& Firth, J. V.) 1-12 (Texas A\&M Univ., 2006). 
15. Thomas, D. J. et al. Warming the fuel for the fire: Evidence for the thermal dissociation of methane hydrate during the Paleocene-Eocene Thermal Maximum. Geology 30, 1067-1070 (2002).

16. Nunes, F. \& Norris, R. D. Abrupt reversal in ocean overturning during the Palaeocene/Eocene warm period. Nature 439, 60-63 (2006).

17. Röhl, U., Westerhold, T., Bralower, T. J. \& Zachos, J. C. On the duration of the Paleocene-Eocene Thermal Maximum (PETM). Geochem. Geophys. Geosyst. 8, Q12002 (2007).

18. Zeebe, R. E. \& Zachos, J. C. Reversed deep-sea carbonate ion basin-gradient during Paleocene-Eocene Thermal Maximum. Paleoceanography 22, PA3201 (2007).

19. Dickens, G. R., O’Neil, J. R., Rea, D. K. \& Owen, R. M. Dissociation of oceanic methane hydrate as a cause of the carbon isotope excursion at the end of the Paleocene. Paleoceanography 10, 965-971 (1995).

20. Zeebe, R. E., Zachos, J. C., Caldeira, K. \& Tyrrell, T. Oceans: Carbon emissions and acidification. Science 321, 51-52 (2008).

21. Dickens, G. R. Carbon addition and removal during the Late Palaeocene Thermal Maximum: Basic theory with a preliminary treatment of the isotope record at ODP Site 1051, Blake Nose. Geol. Soc. Lond. Spec. Publ. 183, 293-305 (2001).

22. Bowen, G. J. et al. A humid climate state during the Paleocene-Eocene Thermal Maximum. Nature 432, 495-499 (2004).

23. van Andel, T. H. Mesozoic/Cenozoic calcite compensation depth and the global distribution of calcareous sediments. Earth Planet. Sci. Lett. 26, 187-194 (1975).

24. Tyrrell, T. \& Zeebe, R. E. History of carbonate ion concentration over the last 100 million years. Geochim. Cosmochim. Acta 68, 3521-3530 (2004).
25. Panchuk, K., Ridgwell, A. \& Kump, L. R. Sedimentary response to Paleocene-Eocene Thermal Maximum carbon release: A model-data comparison. Geology 36, 315-318 (2008).

26. Bice, K. L. \& Marotzke, J. Could changing ocean circulation have destabilized methane hydrate at the Paleocene/Eocene boundary? Paleoceanography 17, 1018 (2002).

27. Dickens, G. R. Rethinking the global carbon cycle with a large, dynamic and microbially mediated gas hydrate capacitor. Earth Planet. Sci. Lett. 213, 169-183 (2003).

28. Sloan, L. C. et al. Possible methane-induced polar warming in the early Eocene. Nature 357, 320-322 (1992).

29. Röhl, U., Bralower, T. J., Norris, R. D. \& Wefer, G. New chronology for the late Paleocene thermal maximum and its environmental implications. Geology 28, 927-930 (2000).

30. Marland, G., Boden, T. A. \& Andres, R. J. Global, Regional, and National $\mathrm{CO}_{2}$ Emissions (CDIAC, ORNL, US DOE, 2007).

\section{Acknowledgements}

The research was supported by NSF grant EAR06-28719 to J.C.Z. and EAR06-28394 to R.E.Z.

\section{Additional information}

Supplementary information accompanies this paper on www.nature.com/naturegeoscience. Reprints and permissions information is available online at http://npg.nature.com/ reprintsandpermissions. Correspondence and requests for materials should be addressed to R.E.Z. 